\title{
Tourism Under Military: A Critique on Land Utilization and Tourism in Postwar Sri Lanka
}

\section{Iraj Ratnayake ${ }^{1^{*}}$ and Mahesh Hapugoda ${ }^{2}$}

${ }^{1 *}$. Department of Tourism Management, Sabaragamuwa University of Sri Lanka, Sri Lanka.iraj@mgt.sab.ac.lk

2. Department of Languages, Sabaragamuwa University of Sri Lanka, Sri Lanka.hapugoda@gmail.com

\begin{abstract}
This critique argues that the intervention of military in land utilization and recreational tourism in the Northern and Eastern provinces of Sri Lanka was instigated by markerdriven geo-political negligence. It discovers that the nature of the introduction of postcatastrophic tourism (Zizek, 2014) has been affected by profound non-articulation of political significance to the traumatic historical memory of the inhabitants who were affected, which has resulted in generating a degree of dark tourism in the area concerned. The southern invasions in the form of usual pilgrims which 'combined battlefield and leisure tourism practices' (Pieris, 2014: 266) has characterized 'the presentation and the consumption of real and commoditized death and disaster area' (Foley and Lennon, 1996: 198) which has originated in consequences of a long term conflict. Correspondingly, the apparent mass tourism promotion by the government between 2009 and 2014 too has significantly disregarded the definitive symbolic principle of 'the visitation to places where tragedies or historically noteworthy death has occurred and that continue to impact our lives' (Tarlow, 2005: 48) before obvious profit motives. The study observes that serious memories and sensitivities of the thirty years of the war-affected community have not been paid attention to and has caused dangerous humanitarian negligence in a wider political sense. While the function of tourism at present as an agent of development in improving the living condition of the community seems evidently true in this context, the trivialization of the symbolic significance of a historical memory and ownership of a community, which has turned 'the suffering into a leisure experience for contemporary tourists' (Smith et al., 2010: 38) cannot also be easily overlooked.
\end{abstract}

Keywords: post-catastrophic tourism, post-war politics, tourism development, land uses, Sri Lanka tourism

\section{Introduction}

Tourism is widely considered 'one of the most remarkable socio-economic phenomena of the twentieth century' (Neto, 2003: 1). Perhaps as the 
largest industry in the world, it functions as a change agent of development (UNWTO, 2013). Therefore governments, especially those in the third world with inherent natural heritage, are unhesitant to include tourism as a main source of income in their economic policy manifestos. In doing so, they often tend to forget the subsequent socio-cultural and political concerns that can have drastic impacts on their communities. There is no argument that some of the potential tourism attractions have to be promoted to uplift the living conditions of the communities concerned. Most importantly, in the precise case under review of this paper, the communities which were subject to thirty years civil war between Sri Lankan government and Tamil secessionists should have been the major concern of any post-war development strategy. It should have been equally significant to realize that their memories of war were also based on certain historical geo-political grievances. When it comes to utilization of land for any development concerns, not only the above geopolitical nostalgia but the ownership of land in those community has to be kept in mind for a better ethnic connectivity since the very foundation of the conflict resulted from geo-political misunderstandings themselves. In this sense, this paper focuses on a phenomenon where the introduction and development of tourism has fundamentally created a negligence of politicoideological and policy implementation nature which are now in conflict with historical socio-political concerns of the community.

To illustrate the said negligence, the study identifies the manner of acquisition and management of lands for tourism purposes in certain post-war areas as potential empirical evidence. Land has been the most prominent grievance for the initiation of the ethnic conflict in the North-Eastern Sri Lanka and the manner in which same aspect is exploited can be assumed as a 'focal target of obliterating the ethnic identity' of the inhabitants in the area. In this very regard, the introduction of tourism has functioned as signifier of the dominant ethnic group whose authority in political decision making has contributed to reaffirm its hegemonic status as master than an agent of sustainable development. Hence, in a restricted sense, both politically and culturally, tourism has not been able to establish trust in a reciprocal sense 'as a rewarding relationship in the communities concerned' (Hunter, 2004: 308). In addition, though the tourist arrivals impressively increased during 2010 and afterwards, as Tourism Watch observes, the Sri Lanka tourism industry has created 'new inequality and is further increasing the conflict rather than bringing peace and crosscultural understanding' (Mangalassery 2010). As a result, in contrast to the promotion of mass tourism, Lokuhetti and Jayawardena (2013) suggest the necessity of a new approach for long lasting peace and a sustainable form of tourism in match with the higher expectation of 2.5 million tourists in 2016.

The study identifies that the Sri Lankan military, with its power and charisma, has functioned to assist the government to acquire lands in controversial zones 
where community resistance is historically seen against the rise of tourism. The said political negligence in tourism derives from the nature and the function of government military as a superimposed agent who acquires and utilizes lands in North Eastern Sri Lanka. Deviating from civil government agencies such as Tourism Authorities, Provincial Councils or Local Government Bodies, the military has used its 'security concerns' to acquire land for tourism especially to overlook their general resistance for tourism and right for land use. Hence a proper channel for a democratic negotiation between the community and political agencies is missing and the type of tourism that exists in these geographical entities patronaged by the military seems alienated from the community igniting further resistance. In addition, certain civil attributes which make tourism industry more community sensitive are also missing in these sites. It is observable that in most of the controversial lands acquired and secured by the military, for instance Peanut Farm in Panama and Thalsevana in Kankesanthurai (KKS), the resorts are commercially managed by the military themselves. Heavily guarded checkpoints, security interrogation in the access points (barricades) to the above resorts, and the constant movements by the security personals in the area restrict authentic tourists' behaviour or create a grotesque sense of unnaturalness.

The nature of tourism that is propagated and operated by the military too significantly deviates from ordinary tourism product that follows protocols made by the Sri Lanka Tourism authorities. Hence the ultimate tourism product that is generated amidst all the controversies has to be analyzed unfolding beyond common narrative of land grabbing and militarization of tourism while sticking to the existing empirical base. The study also remarks that the failure to establish a credible political 'trust' in implementing tourism projects after the war based on universal democratic and humanistic principles has generated series of grievances and resistance toward post-war development in North and Eastern Sri Lanka. However, it can be witnessed that the lack of socio-political concern resulted in the fatal defeat of the then government in the election held in 2015. By analyzing the narratives of the then political authority and reviewing the nature of policy implementation and intervention in land-use activities in the areas where features of mass tourism were forcibly introduced to key nature tourism attractions, this study examines how the denial of a true political articulation based on sustainable development paradigm unfortunately relinquished the element of ethnic harmony and nation building. Further, concerning the basis that the thirtyyear war itself was a product of geo-political sentiments of ethnic nature, the study suggests that the land use policies for mass tourism should be handled with more cautiousness and transparency rather than not being subject to the demand-driven tourist motivation. 


\section{Objectives}

By deriving empirical evidence from the sites subject to forceful land acquisition and tourism operation and reviewing existing literature about the said phenomenon, this study aims to examine the nature of the tourism product generated in the post-war phenomenon by going beyond existing narratives of militarization of tourism and land grabbing discourse. The study observes that the deliberate negligence in maintaining the quality through locally and internationally accepted standards in tourism product has caused serious deviations in the ultimate outcome. It also observes how the absence of civil authorities and channels (both political and administrative) and the presence of military in their place has aggravated the situation in which the communities have been deprived of land rights and fundamental rights. The study articulates the new relationship that has emerged in the war-tone coastal belt between land (mis)-use and the lucrative tourism operation has led postwar Sri Lanka to significant controversies and de-humanization. In the context of lasting historical geo-political grievances that sparked a thirty year war, the study finds that that the short-sighted nature of politico-administrative decisions taken by the contemporary governments over the implementation of tourism as a 'change agent' in the post-war development in Sri Lanka has further intensified misunderstanding between government agencies and affected communities. Instead, the study substantiates the possible rise of high-end tourism in ethnically sensitive geo-political entities in Sri Lanka results in community resentments and disaster capitalism (Klien, 2013).

\section{Methodology}

The information used for this research was based a review of the literature and documents relating to the land use decisions of state sector, institutions and as well as private operators of different scales varying from small to medium scale operators in concerned coastal communities. State sector institutions include those who are with direct involvement in land administration and semi-structured interviews were conducted with officers of those institutions. Informal interviews with local community groups and representatives from non-governmental organisations were also conducted. In addition, participant observation was used to collect primary data and also allowed the researchers to determine the accuracy of the information gained in interviews. The researchers spent a total of 18 days during June and July, 2015 on-site at Arugam Bay, Panama, Pothuvil in the Eastern Coast and Jaffna Peninsula in the North. 


\section{Empirical Evidence}

To examine the nature of land acquisition and utilization and the subsequent operation of tourism in military controlled areas in Northern and Eastern Sri Lanka, two controversial sites have been focused. Shastrawela and Ragamwela from the Eastern Province and Kankesanthurai from the Northern Province are the two entities that are considered from many such examples scattered around the coastal belt in Sri Lanka. Shastrawela in Panama (see Figure 01) has a significant history subject to land grabbing controversies starting from the Tourism Master Plan in 2005 while Kuchchaveli and Kankesanthurai (see Figure 02 ) have been focused on by many recent reports and studies in relation to land grabbing.

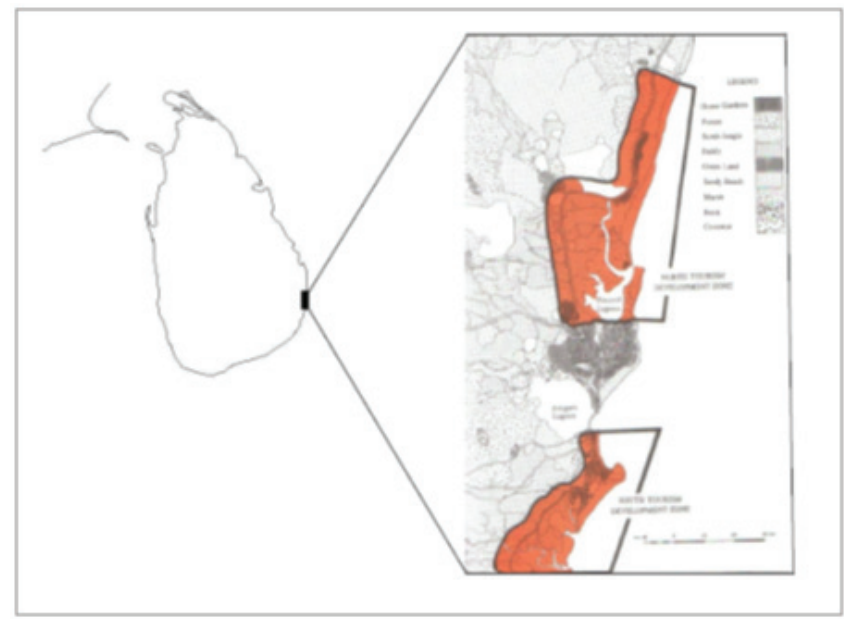

Source: Tourism Mater Plan Sri Lanka 1992-2002, p. 259

Figure 01: Arugam Bay Tourism Development

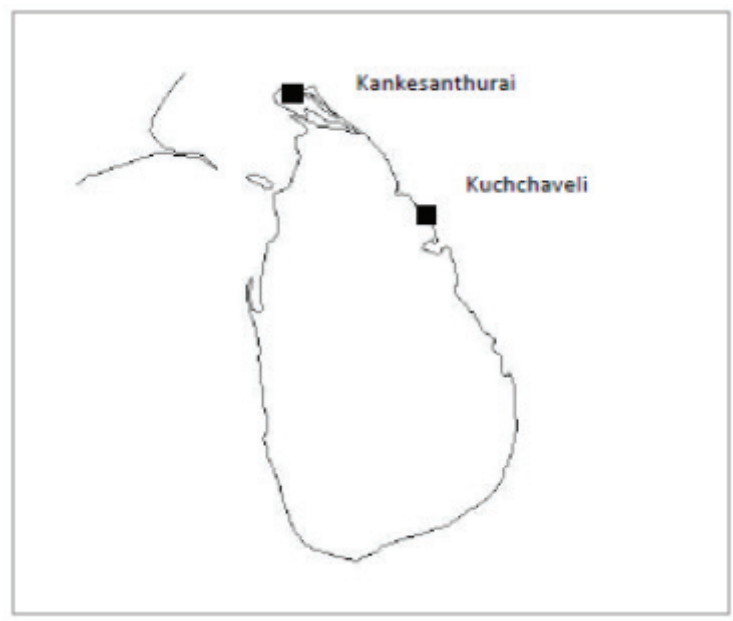

Figure 02: Kankesanthurai and Kuchchaveli Sites 


\section{Shastrawela and Ragamwela Case (South of Arugam Bay)}

The East coast of Sri Lanka offers infinite opportunities for all kinds of active and passive water based recreation. Arugam Bay is a fishing village located in two and half kilometres south of the small town of Pottuvil which is situated in the dry zone of Sri Lanka's remotest southern end of the Eastern coast. Arugam Bay is 320 kilometres away from the capital Colombo and it is one of the most beautiful bays in the island- a popular tourist destination with perfect surfing conditions. It is probably the best surf destination in Sri Lanka and one of the world's top ten surf locations. Hence, the area is of a great attraction especially for the surfers from all over the world.

In late 2004, the Tsunami devastation had severely affected the people in the area and, as a result, most of super-infrastructure facilities were destroyed. Due to its popularity among tourists, the area has managed a slow recovery and the community has developed tourism with their own hard work and inspiration. After the war several other surfing points are now becoming popular namely, Whisky point to the north of Arugam Bay and to the south Peanut farm and Okanda (Respondent 1: Community Representative, personal communication, June 13, 2015). This expansion is obvious as steady tourist concentration turns traditional surfing points busy in the area and the case typically corresponds with destination development proposition.

Tourism potential of land further to south of Arugam Bay such as Shastrawela and Ragamwela villages have been come to surface particularly after the conflict. Pristine wide sandy beach spanning well over several kilometres, the natural forest cover in the hinterland and undulated terrain with sand dunes are attributable for an exemplary beach recreation. The area had been identified already by the second ten-year master plan of Sri Lanka tourism which commissioned in 1992. This plan itself produced several feasibility studies with one for Arugam Bay. The extended development to the north and to the south of Arugam Bay has been proposed in the plan. However, the government was unable to carry out the plan fully due to inconsistent tourist arrivals to the country in general and due to community resistance in particular.

The local community in the area is deprived not being much blessed with opportunities. The main livelihood of the villagers is farming, both paddy and chana (shifting) cultivation. In adequacy in irrigated water supply, paddy cultivation in certain areas is limited to one season leaving inconsistent livelihood options. In addition to farming some families in the panama community involved in fishing but restricted to small scale due to in absence of a fishing harbour facilities in Panama. "The plots of lands were distributed in Shastrawela GN division for 150 families from Panama by the government early 2000 who started farming especially peanuts with the assistance of 
tobacco company" (Respondent 2: Community Representative, personal communication, June 21, 2015).

The situation has been change after the conflict. Considerable increase in tourism demand with sustained peace the government has adopted a new approach to occupy those customary lands of locals. As a result, "... more than 350 families in Ragamwela and Shastrawela villages have been forcibly evicted from their lands by the military (UNESCO, 2013: 3). The government forcibly appropriated these lands in 2010 and handed over to navy and the air force. Peanut Farm is the only remaining plot of privately owned land located in-between the lands occupied by air force and the navy. The present owner who is from Panama Village shared his experiences with us, "I have been operating here since 1997 . Tsunami affected my property in 2004 . However I was managed to start operations back. The situation was changed after the war as the government exerted pressure on us to left these lands. I was threatened over the phone and asked to give up but I was the only one who could survive after all" (Respondent 3: Owner/Peanut Farm Surfing Point, personal communication, June 27, 2015). The presidential secretariat was directly involved in the land grabbing. This incident alone created an colossal unrest among villages.

After this appropriation land use decisions were abruptly taken by the military. These decision were profoundly ad-hoc where the land has been used for the construction of a hotel and an intentional conference centre. These projects have been carried out by Navy and the Air Force respectively, neglecting protocols of such development. For instance, relevant governmental institutions have not been consulted from the outset. "Air force did not allow Coast Conservation Department to entre to the site for inspection and navy too did not obtained proper permission from us to initiate their construction within the area under our custody" (Respondent 4: Planning Assistant/CCD, personal communication, June 29, 2015). Responded 4, further asserted that, CCD had to obtained a court order to oversee the construction work by air force which had to temporarily suspended and navy was started negotiating and coordinating with the CCD. This case typically evident that ad-hoc nature of decisions taken by the developers sheer violation of existing legal framework of the country" (Respondent 4: Planning Assistant/CCD, personal communication, June 29, 2015). Due to continuous pressure exerted by the villagers the present government has decided to release the land except 25 acres that occupied for the construction of an international conference centre by the air force (Divaina, July 19, 2015). The whole process is unforeseen. "Nothing was transparent. Initially we were told that this land is for a military base and later to construct a housing scheme for war heroes, but after all they did something different" (Respondent 2: Community Representative, personal communication, June 21, 2015). 


\section{Kankesanthurai and Kuchchaveli Case}

Kankesanthurai (KKS) is one of the prominent examples of forceful land occupation by military after the war where the area has been declared as a high security zone (HSZ) on the northern tip of the Jaffna peninsula. This much controversial land grabbing that occupies some 5000 acres of heredity lands of locals has not been exclusively occupied for military purpose but also for recreation facility development called Thalsevana Holiday Resort formally known as Harbour View Hotel. It illustrates the case that new phenomenon in the post war period where the recreational business has been added onto military portfolio.

We have several important observations during our first visit to Thalsevana. First, we had to register ourselves at a security point just before the HSZ. And also security questioned us about a reservation which sounds not welcoming at all. We travel further about few kilometres passing several military and police units which were on the both sides of the road until reaching the resort. A prime plot of land right in the centre of the HZS of KKS- with a strip of beach and immediate waterfront has been used for the recreation that typically follows the same process elsewhere from design to construction and operation. The guests are being served by all in-service military personal and as a result local do not find any employment opportunities here in these resorts. At time of the site visit, several Navy crafts were patrolling out in the sea was no addition to the ambience of the resort but might registering a concern in the minds of guests whose aspirations were otherwise.

Kuchchaveli is a small fishing village located 34 kilometres to the north of Trincomalee in the north-east of Sri Lanka. Fishing and agriculture are the main livelihoods of the local community which had largely been disturbed not only the times of the war but also the after. At the end of the war, considerable extent of land in Kuchchaveli was occupied by the Sri Lankan Navy. The villagers had to leave their own homes, their farms, and their fishing areas. The Navy occupation has been continued even after the war and as a result locals could not return to their lands. Instead, the Government had other plans for the land. A saltern was started in the lagoon with private investment that impede lagoon fishing permanently. Sri Lanka Guardian (2011) reveals a proposal that allocate fifty-one blocks of state land reserved exclusively for resort development in Kuchchaveli . Community representatives claim that, neither public notification nor consultation has been taken into consideration and the 'process adopted deliberately attempts to circumvent constitutional provisions pertaining to state land' (Sri Lanka Guardian, 2011). Navy occupation was deliberately done as a strategy for thwarting the resistance from locals who are desperate to facilitate their own residence and livelihood. 


\section{Discussion}

Land has been a chief concern in Sri Lankan society dating back to colonial times. Its distribution, scarcity and location have led to deeper geo-political issues that have historically affected to even rewrite its chronicle. In its modern economy, from the inception of formal tourism, tourist product development, conservation, preservation and protection have been given a high priority through land zoning and tourism legislation. Tourism has come to stay as a significant sector in the national economy of Sri Lanka. For example, overall contribution of tourism to the national economy is about 2 percent of Gross Domestic Product (GDP). It is the fourth largest foreign exchange earner in the balance of payments in Sri Lanka (Sri Lanka Tourism Development Authority, 2013). Since it has been accepted as a development option in the country, maximisation of economic benefits such as foreign exchange, employment, government revenue, etc., is given priority by the government (Samaranayake, 1998). In order to achieve this, it is needed to support tourist attractions and facilities and to attract a best possible number of tourists. Therefore, product development is considered as a major tourism development strategy (UNDP/ WTO, 1992). As product development activities essentially create land use conflicts it compulsorily involves land use planning. The controversies about land use for tourism started increasing alarmingly after the ethnic civil war in 2009 when tourism was chosen as a major agent of economic development in post-war Sri Lanka.

Tourism in Sri Lanka, from a land use perspective, involves mainly activities in the beach areas, cultural heritage sites and wildlife matters. The popularity of the beach holiday among the predominantly Western European winter tourists is evident from the high occupancies in the beach-oriented hotels in winter. Approximately half of the average duration of stay of a tourist (7-8 days) is spent near the beach. Some 1000 miles of coastal area in the country are extensively utilized for tourism product development. This accounts for the large cluster developments of hotel facilities by the beach and about 75 percent of the graded hotels in Sri Lanka and 80 percent of the hotel rooms are located in coastal areas (Ranasingha, 1997).

\section{Paradigm Shifts in Sri Lanka Tourism}

Until late 1960s tourism has not been recognised as an emerging sector in the economy as well as in the society. But later in the decade relatively significant flows of tourists started to be visible, the government involvement was inevitable in handling various aspects of the industry including planning, development and management of large movement of people (Bandara, 2003). Further, Bandara (2003) observes two paradigm shifts in Sri Lanka tourism. During the early stages, the approach was development for tourism because 
the country had to focus on development in order to contain tourism as an industry in the economy; which has been changed later on the where tourism has been recognized as an option for development. However, the tourism development in general was demand driven and mass tourism still constitutes a segment occupying a prominent position in the overall tourist market of Sri Lanka. Tourism development in the post-war is a mere continuation of the latter but in the presence of new issues, problems and challenges that dilute the strength of tourism development strategy of the country.

The war was ended in 2009. However improved security situation in the country brought new hope into Sri Lanka tourism but is development decisions have been taken haphazardly. Local value added proposition has not been fitted into the model of post-war tourism development in the country. As a result, tourism as a change agent has come to surface than ever before but extensively disturbing existing systems of community life that were subject to change at much slower phase. The nature of tourism as a consumption-heavy industry and in which the development is predominantly demand-driven are the factors mainly accountable for the present context of tourism development that could empirically witnessed today. Literally development decisions are made in the absence of a well defined policy and also in the context of power imbalances especially in conventional rural settings leaving a myriad of complex but clearly identifiable set of issues.

\section{The Post-war Experience}

In the atmosphere of the necessity to 'next massive leap forward' the much stagnated economy due to war and to transform it as an influential economy in Asia (Mahinda Chinthana: Ministry of Finance and Planning, 2010), Sri Lanka was expected to experience a rapid development in the tourism industry by increasing the number of tourists visits. The vision of the rapid economic development of the then government has been, according to the above Mahinda Chinthana policy manifesto, 'is to transform Sri Lankan tourism sector, by 2020, to be the largest foreign exchange earner in the economy' (164). This vision was coupled with its mission to make Sri Lanka a strategically important economic the centre in the world making it also a commercial hub of Asia. Since tourism was identified as a main source of national income in the anticipated economic growth that was believed to 'rebuild' Sri Lanka, it was given a prioritized area in sustainable economic development encompassing everything else. The Minister of Economic Development, the most powerful Minister during the 2009-2014 era, was assigned to handle the tourism industry with great anticipations. Together with a wide promotional mechanism, the Ministry started parallel activities which targeted to attract mass tourists. To accelerate the functionality of tourism and to build the necessary infrastructure the Ministry of Defence too contributed 
to various face-lifting activities in the central capital and peripheral zones where tourism was deemed to operate as a major commercial contributor to the national economy. When the military personals were used to negotiate with civil activities, and when its significance had been heavily felt to be effective by the general public right after the victory of the thirty years war, there had been very little protest for their intervention in public (non-military) appearances. The government tactically used the symbolic achievement of the military forces to silence the public in sensitive issues such as commercially benefitting land related matter, commercially productive projects where community resistance can spring up, public evacuations or dislocations were needed in congested city areas, start certain controversial projects where there had been historically marked community resistance. It is during this season that the Sri Lankan military forces got directly involved in tourism related activities in some of the most controversial areas. However, the function of the military in the field of post-war tourism in Sri Lanka can be identified under two major sections.

a. Its trained manpower was effectively and probably cheaply utilized to enhance the most needed infrastructure and face-lifting activities both in North and East as well as in the central capital.

b. The victorious symbolic power of the military forces was used to acquire lands that are of commercial valuable in the country by 'showing' their strategic military significance while successfully thwarting community resistance for tourism.

In addition to these attributes, it was observable that some sort of 'dark tourism' was emerging in Northern and Eastern Sri Lanka when there was a brief period between 2009 and 2012 in which thousands of locals from South started travelling to see the monuments of war. The trend of post-catastrophic tourism focused on areas where the final stage of the civil war took place. They were first group of visitors who travelled to the areas which were captured by Tamil Tigers for nearly three decades. The Sri Lankan military started small cafeterias and rest houses alongside the A9 road to cater the unmanageably pouring crowd to Northern Peninsula to witness the remnants of devastating war. Later the military forces went into the lucrative tourism business by putting up luxury hotels and resorts near the beaches or any other nature tourism attractions. From 'dark tourism' now it has gained momentum to mega tourism in many areas where it has been declared as High Security Zones (HSC), there are resorts and hotels that are maintained by the Sri Lankan military.

The tourism model that was supposed to implement in the post-war context was borrowed from the Tourism Master Plan that came about somewhere 
in the early 1990s. It aimed to establish a series of hotels and resorts that facilitate rich tourists who seek high-luxury tourists' destinations. The Plan intended to develop Arugam Bay as 'a model for an up-market, boutique tourism destination though tourism in the village was historically low budget' (Robinson and Jarvie 2008: 640). The Task Force TAFREN further suggested that 'the local population was to relocated from the 200-meter protected zone. Although this land is privately owned and falls outside the governmentregulated 200-meter limit, the area was to be redeveloped for hotels and tourism infrastructure' (641). The then Chairman of the Tourist Board had made it clear in one of the post-tsunami Arugam Bay meetings, 'we are looking about the high level tourists, not the 5 dollar tourist' (cited in Braunmuhl et al., 2006). In advanced rhetoric, as quoted by Naomi Klien, Sri Lanka Tourism Board saw the tsunami disaster as a blessing in disguise, 'In a cruel twist of fate, nature has presented Sri Lanka as an unique opportunity, and out of the great tragedy will come a world class tourist destination' (Klien 2007: 11). 'Promoting highend tourism seems to be one of the driving forces of TAFREN, which seems geared towards encouraging high-end tourism, export-oriented agriculture and manufacturing, and large scale fisheries. It clearly does not include smallscale fishing, subsistence farming or community based tourism' (Fernando as cited in Klien 2005).

It is clear that the post-war tourism had learnt straightaway from the initial objectives of the Tourism Master Plan in 2005 which was designed for rebuilding the tsunami affected community in Arugam Bay. The 100-meter Tsunami Buffer Zone which was meant for safety measure was not applied for tourism. 'On the surface it made sense, but there was a glaring problem with that rationale- it was not being applied to the tourism industry. On the contrary, hotels were being encouraged to expand into the valuable seafront where fishing people had lived and worked' (Klien 2007: 388). She further states, the federal government had commissioned a team of international consultants to develop a construction blueprint for Arugam Bay, and this plan was the result...it called for Arugam Bay to be levelled and rebuilt, transform from a hippie-charming seaside town into a high-end boutique tourism destination' (388). According to Klien, this kind of plan was initiated with the motivation of the United State government backed by theories adopted by Chicago School of Economics (392). As she examines, 'The US government was so enthusiastic about Sri Lanka's potential as a high-end tourism destination, with all its possibilities for resort chains and tour operators, that USAID launched a program to organize the Sri Lankan tourism industry into a powerful Washington style lobby group (392). The land that was targeted under the 2005 Master Plan, the stretch of the coastal belt consisting of 150 acres from Panama to Potuvil, was indeed what was at present taken into a naval military base wherein a tourism resort is managed by the military themselves. 
The reason why such transformation to high-end tourism was desired by the then authorities was because of the tremendous potential for tourism in the area under consideration. The natural fauna and flora, beautiful beach with surfing potential, wildlife and possibility for adventure tourism attract the investors for this priceless entity which is at present covered with barbwires and protected with military personals. The land which was once used by the community for various daily activities is now exclusively a military location. As the local community was deprived of access to their historically used lands, they sought legal means to get back what they so far entertained. At the same time, the local community launched rallies and protested against the government for their land rights claiming that they have historically used these lands agricultural and fishing purposes. These protests were often covered by the local media. However, the following observations could be made in a series of site visits by the researchers.

\section{By-passing civil administrative practices and new implications of land acquisition}

Community resistance against tourism has been a common phenomenon around the world. The Sri Lankan experience in this regard has been no difference. Communities resist tourism for various reasons such as cultural alienation, exploitation of eco system and environmental degradation or misalignment of economical benefits. To establish tourism with community's consent is a time consuming and tedious activity but enhancing community awareness is the only sustainable and lasting mean. Democratically practiced civil means to negotiate community matters, listening to their grievances, interfering to their issues in a rational way, enhancing their awareness about the function of tourism, its negative outcomes and how to minimize them are the standards methods to improve the understanding between community and the function of tourism in the developing world. However, what can be observes both Shastrawela in Panama and Kankesanthurai in Jaffna are arbitrary and forceful introduction of tourism managed by Sri Lanka military. Hence the democratic practices of civil agencies in these areas are minimal or completely lacking in bringing about understanding between these two mutually exclusive entities. For example, information from District Coordinating Agencies or grievances from local political bodies are not met with higher policy implementing bodies such as Ministry of Tourism or Economic Development. The community organizations are not allowed to talk to the military that actually possess the lands and operate tourism resorts in these areas (see Figure 03).

As a result, the above by-passing has generated serious implications about land ownership and its commercial use, function of tourism, traditional livelihood etc. Some of the cases have ended up in courts and the community does not seem to trust the way these project are implemented and doubt whether they are 
of any benefit to them. The military is not the ideal body to manage a sensitive subject like tourism which brings in community demands and commercial motives to paradoxical juxtaposition.

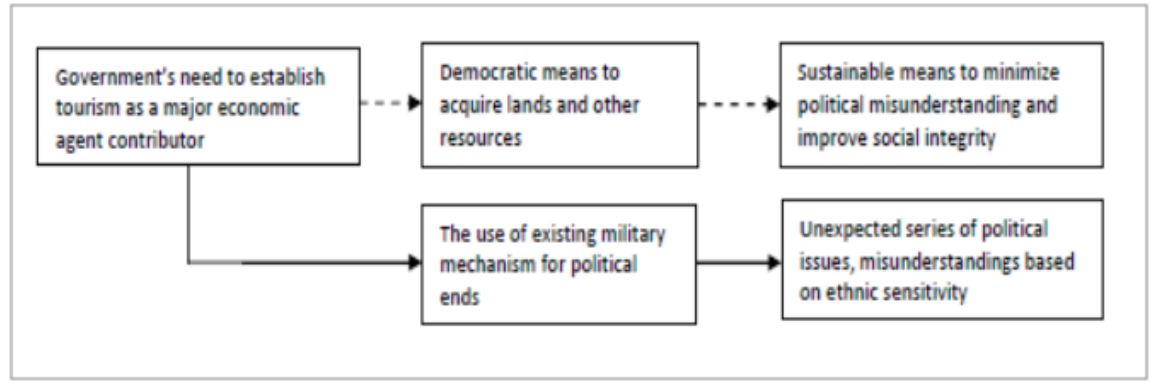

Figure 03: Mmilitary-political strategy in land acquisition and implicate

\section{Seriously superimposed tourism instead of community-friendly and inclusive}

As evidenced by Klien (2005) and Robinson and Jarvie (2008), Shastrawela in Panama has been aimed for the utilization of hotel and resorts targeting mass tourists. In this case, the land that was recommended under the 2005 Tourism Master Plan for its potential for tourism has now been occupied by the Sri Lanka Navy. The negative impacts of having such a state monopoly seem to far outweigh the benefits mentioned above. With increasing population, rural people have been compelled to encroach on state lands through sheer necessity. Adding to this challenge are the economic, social and environmental impacts of continued degradation of Sri Lanka's land resources from misuse and overexploitation. Therefore, the clearing of lands for other uses such as tourism is a big problem. Moreover, competition for land among various users including tourism will, inevitably, become a more pressing problem. Under this context, military was an effective mean to take control of the commercially conducive lands for tourism purpose and to silence the community resistance after the war. The arbitrary use of military leads to various other issues due to lack of guidance and supervision by tourism experts who can function as 'gobetweeners' between the government agencies and communities. The military has no ideas how they violate the universally accepted tourism protocols, civil and human right conventions, land use policies, feasibility standards and standards for resort construction and management, incorporation of other government bodies such as tourism authorities and other expertise.

\section{Negligence of geo-political sensitivity of historical and political nature}

Most of the areas that were considered for tourism promotion, as previously explained, were situated in the coastal belt in the Northern and Eastern Sri Lanka. The natural beauty and the diversity of environment were the main 
reason for the exotic tourists' attraction in these areas not-visited by people for nearly three decades due to the war. The thirty years of civil war also not only explored in most part of the coastal areas where many of these tourism projects were initiated but it was also area where the final battle of the Tamil Tigers historically took place. When it comes to certain tourism projects in Mullivaikkal, which was located in the North-Eastern tip of Vanni district where the final battle between the Sri Lankan military and the Tamil Tigers took place, the possible war memories of the Tamils in that area was completely taken for granted in the face of forceful implementation and operation of military tourism. The initial reason for the local tourists from Southern Sri Lanka to come here is to see the 'victorious remnants' of war. Unlike the Sri Lankan military who builds tourism resorts over their victorious grounds, the Tamils may feel that it is this 'conquered' battle field that is 'visited' by the outsiders for entertainment. In a multiethnic and multilingual country where there has been historical battle for political identity, a government has to be careful in implementing commercially feasible projects which can hurt the historical sentiments of another community. It is said that the original owners of these lands cannot even see those while the outsiders can go and enjoy in these resorts built in those lands. Hence this paper suggests that the true 'invasion' has taken place not in terms 'dark tourism' (Pieris, 2004) made of timely inspired Sinhalese visitors right after the war but in terms of commercially driven mega scale tourism projects that made way to these areas and are here to stay forever.

\section{Findings}

The implications of the government's approach in land grabbing and land use decision in connection with tourism by the military has created several repercussions. Firstly, military involvement in tourism has largely ignored the necessary consultation of other governmental institutions that have direct stake in land use decisions. It has been clearly evident that the military has bypassed all protocols that need to be encompassed. This involvement seemed unquestionable resulting infringement social order by and large. As the cases highlighted this has turned out at d stages form site development to operations.

Secondly, Lack of transparency in the development agenda has also created frustration among the deprived people. Their voices have not been heard. On one hand, this development remained inaccessible to locals as it was typically enclave in nature, and at the cost of largely disturbed traditional livelihoods of locals on the other. Loss of heredity land had left nothing but the frustration. It is reasonable to question this development model, since even with top-down development approach would take such issues into consideration at grass root level. 
Thirdly, public access has been restricted particularly to the beach at locations occupied by military. Function of a tourist resort has seemed to be redefined as tourism operations at these locations typically not corresponding with conventional resort operation. For instance, one must declare his or her identity by producing travel documents at security check-points manned by military personal. We have personally experienced that walk-in guests are not welcome at those resorts as it was questioned often for the confirmed reservation. And in such premises are not totally free from military presence as regular operations including security have been carried out by military personal.

Fourthly, in order to negate the resistance from local, the government's land grabbing strategy came to effect with national security concerns on the top of the agenda. Restricted or controlled tourism operations by the military occupying potential land led to new dimension of the issue. The developers unable to capitalize the full potential of these lands as land use decision were taken in absence of policy directives and a proper land use plan. Combined military and resort operations will further deteriorate the existing potential for tourism as whole leaving an unsolved land use conflict in the long run.

The ultimate tourism product that had resulted from among these controversies does not, on the other hand, stick to accepted standards of quality maintenance and supervision. Except the comments given in the TripAdvirsor and other virtual entities, the quality of service given to customers are not accounted for standards laid out by tourism authorities, neither to any other relevant authorities who is responsible for consumer care. The architectural designs for the resort lay-out, quality of food, service quality and delivery, safety measures, etc. are all decided and delivered by the respective military authorities, mostly Sri Lankan Army and Navy. The exclusive nature of the product may sometimes inspire the some exotics military tourism but surely leads to deficiency of acceptable tourism standards.

Especially, in resorts such as Thalsevana in KKS scrutinizing in the checkpoints, interrogation over hotel reservation, registration of vehicles for high security reasons etc. were common while heavily mobilizing military personals were also observed during the empirical survey, which may inspire further studies with regard to tourists' perception. It will be a brand new area of study how tourists both local and overseas behave in a site constantly observed and overseen by the presence of military.

\section{Conclusion}

The study finds that the areas considered in the study have been subject to serious land acquisition inequities and controversies. Despite the rhetoric of 
development, lack of transparency in the development agenda has also created frustration among the deprived people. The presence of military in the place of civil administrative bodies in land acquisition and later utilization for tourism operation has caused misunderstanding in the communities concerned. The relationship that has emerged in the war-tone coastal belt between land (mis)-use and the lucrative tourism operation has led post-war Sri Lanka to significant controversies and de-humanization. In the context of lasting historical geo-political grievances that sparked a thirty year war, the study finds that that the short-sighted nature of politico-administrative decisions taken by the contemporary governments over the implementation of tourism as a 'change agent' in the post-war development in Sri Lanka has further intensified misunderstanding between government agencies and affected communities. Instead, the study substantiates the possible rise of high-end tourism in ethnically sensitive geo-political entities in Sri Lanka results in community resentments and disaster capitalism (Klien 2013).

\section{References}

Bandara, H. M. (2003). Tourism Planning in Sri Lanka. Pannipitiya: Stamford Lake

Braunmuhl C. V. (2006). Tsunami: A study on disaster response in Sri Lanka. Colombo: Media International

Divaina (July 19, 2015). Panam Patthtuwe Kandulu Matha Hotal (in Sinhala). Divaina E-news Paper. Retrieved on http://epaper.divaina.com/index. php?option $=$ com_flippingbook\&view $=$ book\&id $=2299 \&$ page $=1$ on July 19, 2015. p IX

Hunter, W. C. (2004). Trust between Culture: the Tourist. in Stephen Williams (Ed.), Critical Concepts in the Social Sciences. London: Routledge. pp 279-296.

Klein, N. (2007). The shock doctrine: The rise of disaster capitalism. New York: Metropolitan Books

Lokuhetti, A. and Jayawardene, C. (2013). Developing a shared vision for tourism in postwar Sri Lanka. Emerald, Vol. 5 Issue 5.

Foley, M. and Lennon J. J. (1996). Dark Tourism. London: Continuum

Mangalassery, S. (2010). After the civil war: Sri Lanka relies on tourism. Retrieved on Jun2 02, 2015 from http://www.tourism-watch.de/en/ content/after-civil-war-sri-lanka-relies-tourism

Ministry of Finance and Planning (2010). Mahinda Chinthana: Vision for the Future Sri Lanka: The emerging wonder of Asia. Colombo: Ministry of Finance and Planning 
Neto, F. (2003). A New Approach to Sustainable Tourism Development: Moving Beyond Environment Protection. New York: United Nations.

Pieris, A. (2014). Southern invasions: post-war tourism in Sri Lanka. in Postcolonial Studies, Vol.17 No. 3., London: Taylor and Francis.

Ranasingha, I. (1997). Effectiveness of Coastal Set-back Standards as a Nonstructural Solution for Managing Coastal Land in Sri Lanka, Paper read at Conference on Coastal and Ocean Management, Massachusetts, Boston, USA

Robinson, L. and Jarvie, J. K. (2008). Post-disaster community tourism recovery: the tsunami and Arugam Bay, Sri Lanka. in Disasters. Vol.4. No.32. Oxford: Overseas Development Institute. Mercy

Corps, Journal Compilation: Blackwell. pp. 631-645.

Samaranayake, H. M. S. (1998). Development of Tourism in Sri Lanka and Its Impact on the Economy and Society, in A. D. V. De Indrarathna (ed.), Fifty Years of Sri Lanka's Independence - A Socio-Economic Review. Colombo: Sri Lanka Institute of Social and Economic Studies. pp 292310

Smith, M., Macleod, N., Robertson, M. H. (2010). Key Concepts in Tourist Studies. London: Sage.

Sri Lanka Guardian (2011). Sri Lanka accused of waging 'silent war' as Tamil land is appropriated by army. Retrieved on http:/www.theguardian.com/ global-development/2015/may/28/sri-lanka-army-land-grabs-tamildisplacement-report-oakland-institute

Sri Lanka Tourism Development Authority (2013). Annual Statistical Report - 2013. Colombo: Sri Lanka Tourism Development Authority

Tarlow, P. (2005). Dark Tourism: The appealing dark side of tourism and more. in Niche Tourism, Contemporary Issues Trends and Cases. Oxford: Elsevier. pp 47-58.

UNDP/WTO (1992). Sri Lanka Tourism Development Plan 1992-2002. Madrid: UNDP/WTO

UNWTO (2013). Sustainable Tourism for Development Guidebook: Enhancing Capacities for Sustainable Tourism for Development in Developing Countries. Madrid: World Tourism Organization.

Zizek, S. (2014). Living in the End Times. London: Verso. 